\title{
Altered Serum Chitotriosidase Activity and Irisin Level in Obese Children
}

\author{
Obez Çocuklarda Değişen Serum Kitotriosidaz Aktivitesi ve İrisin Düzeyi \\ Ferit Durankuş $^{1}$, Evrim Şenkal ${ }^{1}$, Ramazan Durankuş ${ }^{1}$, Eda Sünnetçi Silistre ${ }^{2}$, Oya Sayın ${ }^{3}$, \\ Nihan Potas ${ }^{4}$, Yakup Albayrak ${ }^{5}$ \\ ${ }^{1}$ İstanbul Medeniyet University, Göztepe Education and Research Hospital, Department of Pediatrics, İstanbul, Turkey \\ ${ }^{2}$ İstanbul Training and EducationHospital, Department of Pediatrics, Istanbul, Turkey, \\ ${ }^{3}$ Research Laboratory, Dokuz Eylul University Faculty of Medicine, Izmir, Turkey, \\ ${ }^{4}$ Ankara Hacıbayram Veli Univ. Faculty of Economics and Administrative Science, Dept. of Healthcare Managment, Ankara, Turkey \\ ${ }^{5}$ Tekirda ̆̆ Namık Kemal University, Medical School, Department of Psychiatry and Behavioural Neuroscience, Tekirdă̆, Turkey \\ Yazı̧̧̧a Adresi / Correspondence: \\ Ferit Durankuş \\ İstanbul Medeniyet University, Göztepe Education and Research Hospital 34035, Kadıköy, İstanbul \\ T: $+905059150161 \quad$ E-mail : feritdr35@gmail.com \\ Geliş Tarihi / Received : 18.02.2021 Kabul Tarihi / Accepte: 22.08.2021 \\ Orcid :
}

Ferit Durankuş https://orcid.org/0000-0002-3337-8419

Evrim Şenkal https://orcid.org/0000-0002-3075-2348

Ramazan Durankuș https://orcid.org/0000-0001-6131-9822

Yakup Albayrak https://orcid.org/0000-0002-1926-1695
Eda Sünnetçi Silistre https://orcid.org/0000-0002-6871-8858 Oya Sayın https://orcid.org/0000-0003-0879-9091 Nihan Potas https://orcid.org/0000-0002-0393-3135

( Sakarya Tip Dergisi / Sakarya Med J 2021, 11(3):523-532) DOI: 10.31832/smj.882608

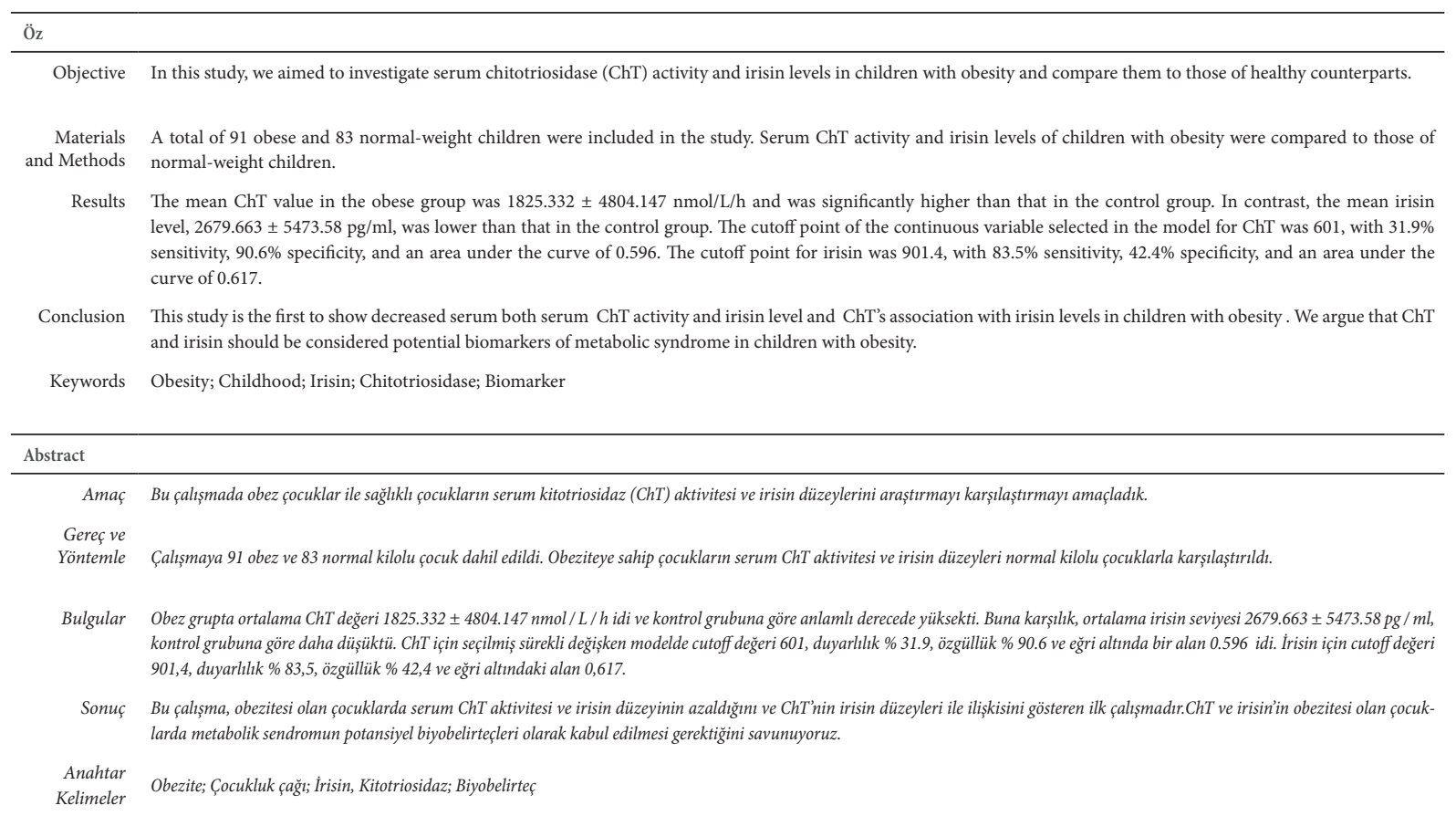




\section{INTRODUCTION}

Childhood obesity is a serious and growing public health problem worldwide. ${ }^{1-4}$ It is associated with short- and long-term comorbidities, including insulin resistance (IR), arterial hypertension, metabolic syndrome, type 2 diabetes mellitus, obstructive sleep apnea syndrome, as well as psychological problems during childhood and adolescence. Childhood obesity commonly persists as a problem in adulthood, and it can pose a higher risk of early mortality. ${ }^{5-8}$ Childhood obesity is described as an excessive accumulation of body fat, which undermines health according to the World Health Organization (WHO). ${ }^{8}$

The association between chronic low-grade inflammation and obesity is well established., ${ }^{9,10}$ Although the exact mechanism of action of this association is not clear, it has been suggested that obesity-related inflammation might be responsible for the impairment of various systems of the body. ${ }^{11-13}$ Several inflammatory markers, including C-reactive protein (CRP). TNF- $\alpha$, IL-6, IL-10, and adiponectin, have been investigated to clarify the association between obesity-related inflammation and cardiovascular events and tissue injury. ${ }^{14,15}$

In the last decade, chitotriosidase (ChT) has been considered a promising inflammatory marker. ChT belongs to the human chitinase glycosyl hydrolase family 18 , and it is produced in activated macrophages. ${ }^{16-18}$ Adipokines (i.e., adipocyte-secreted proteins) and myokines (i.e., myocyte-secreted proteins) are known to be involved in the pathophysiology of obesity-associated metabolic and vascular diseases. It has recently been suggested that irisin, a member of the myokine family, could reduce obesity and improve glucose metabolism. ${ }^{19}$

In this study, we aimed to investigate the serum ChT activity and irisin levels in children with obesity and compare them to those of healthy counterparts. We hypothesized that serum ChT activity and irisin levels would differ between obese and healthy children and would be associated with each other, as well as with other metabolic parameters.

\section{MATERIAL and METHODS Study Population}

The study was conducted at Istanbul Training and Education Hospital and Istanbul Medeniyet University, Department of Pediatrics, between January and September 2019. The study group consisted of children with obesity. The inclusion criteria were as follows: obesity, as defined by WHO Reference 2017 (body mass index-standard deviation score [BMI-SDS] above 2) and the mean BMI-SDS by gender, no endocrinological diseases, no comorbid diseases, ability to cooperate for anthropometric measurements, no psychiatric disorders, mental retardation, or autism spectrum disorder, and willingness of their parents to consent to their children's participation. ${ }^{20}$ Children who had comorbid diseases, mental retardation, or autism spectrum disorder and children whose parents did not consent to their participation were excluded. The control group consisted of children whose weight was normal (BMI-SDS between -1 and 1 ). The inclusion criteria were as follows: ability to cooperate in anthropometric and other measurements that would be used in the study and willingness of their parents to consent to their participation. Children whose parents did not consent were excluded. According to the inclusion and exclusion criteria, 91 obese and 83 normal-weight children were included. All parents signed written informed consent forms after being provided with a detailed description of the study. Present study was designed as case -control comparison. The present study was approved by Medeniyet University Non-Invasive Clinic Research Ethical Committee ( Date: 03 July 2019; Approval Number: 2019/303). This study was performed according to the standards for biomedical research on human subjects set by the Declaration of Helsinki. Before the operations, all patients provided that their records could be used in the present study. 


\section{Anthropometric Assessments}

Anthropometric measurements, as body weight and height were assessed by authors. The measurements were made while the children wore only underclothes and no shoes. Height was measured to the nearest $0.1 \mathrm{~cm}$, with a portable SECA stadiometer Model 213 (SECA, Hamburg, Germany). Body weight was taken to the nearest $0.1 \mathrm{~kg}$ using a SECA digital weighing scale Model 803 (SECA, Hamburg, Germany). Measurements were made two times for confirmation of the results. Body mass index (BMI) was calculated by dividing the measured weight $(\mathrm{kg})$ by the square of height (m2). Anthropometric status was classified according to the age- and sex-specific WHO growth reference using the WHO AnthroPlus 1.0.3 (World Health Organisation, Geneva, Switzerland). The values were follows; WHO Reference 2017, that is: Low weight (BMI-SDS $\leq-1$ ); normal weight (BMI-SDS $>-1$ and $\leq 1$; overweight $($ BMI-SDS $>1$ and $\leq 2)$ and obese (BMI-SDS $>2$ ).

\section{Blood Sampling}

A biochemistry technician who was blinded to the study groups performed the blood sample analyses. The blood samples were obtained in the morning after 12 hours of overnight fasting and placed in tubes with EDTA $(1 \mathrm{mg} /$ $\mathrm{ml})$. The plasma was split by centrifugation at $4{ }^{\circ} \mathrm{C}$ and stored at $-80^{\circ} \mathrm{C}$.

\section{Biochemical Analysis}

Blood glucose and glycosylated hemoglobin A1c (HbA1c) were assessed by the glucose-oxidase method and anion-exchange high-performance liquid chromatography (HPLC). The serum insulin levels were measured by radioimmunoassay. The homeostasis model assessment of IR (HOMA-IR) and insulin secretion (HOMA- $\beta$ ) were calculated using the following equations: HOMA - IR = fasting insulin FINS microunits/milliliter $\times$ FBG millimoles/liter $\div 225$ and HOMA $-\beta=20 \times$ FINS microunits/ milliliter $\div$ FBG millimoles/liter -35 . Total cholesterol (TC), triglycerides (TG), high-density lipoprotein cholesterol (HDL-C), and low-density lipoprotein cholesterol
(LDL-C) were measured using an enzymatic autoanalyzer (Beckman Coulter, CA, USA). The liver and renal function profiles were also determined with an autoanalyzer (Beckman Coulter, CA, USA). Hemogram analysis was also performed using an autoanalyzer (Sysmex 1500, Sysmex Europe, Germany).

\section{Serum Chitotriosidase Activity and Irisin Level Measurements}

Blood samples for irisin and chitotriosidase measurements were centrifuged immediately after collection, and the serum samples were stored at $-80^{\circ} \mathrm{C}$ until the day of analysis. Serum human irisin measurements were performed using a human irisin enzyme-linked immunosorbent assay (ELISA) commercial kit (catalog No. SG10179; Sinogeneclon Co., Ltd., Hangzhou, China) according to the manufacturer's protocol (sensitivity: $1.0 \mathrm{pg} / \mathrm{ml}$; intra-assay coefficient of variation $[\mathrm{CV}]$ : $<8 \%$; inter-assay $\mathrm{CV}$ : $<10 \%)$. Serum human chitotriosidase (CHIT1) measurements were performed using a human chitotriosidase ELISA commercial kit (catalog No. SG1188; Sinogeneclon Co., Ltd., Hangzhou, China) according to the manufacturer's protocol (sensitivity: $7.8 \mathrm{pg} / \mathrm{ml}$; intra-assay $\mathrm{CV}$ : $<8 \%$; inter-assay $\mathrm{CV}:<10 \%)$.

\section{Statistical Analysis}

Power analysis was performed to determine whether the sample size was sufficient for the study. For the comparisons between the obese and control groups, the t-test, Mann-Whitney $U$ test, and Pearson chi-square test were performed for two independent samples. At the same time, the normal distribution assumptions Shapiro-Wilk normality test was used. The Mann-Whitney U test was performed for data that did not fit the normal distribution. In the correlation analysis, Pearson's correlation coefficient was assumed to be normally distributed. However, as chitotriosidase and irisin did not fit the normal distribution, Spearman's correlation coefficient was used for the correlation analysis. Receiver operating characteristic (ROC) analysis was used to choose the most appropriate cutoff 
points for chitotriosidase and irisin. We also tried to predict chitotriosidase and irisin levels using multiple regression with the ordinary least squares (OLS) method. However, assumptions were not provided because the errors were not normally distributed and there were too many outliers in the obese group to be excluded from the study. Therefore, we used quantile regression $(\mathrm{QR})$ as a more robust method to predict the chitotriosidase and irisin levels. The statistical analyses were performed with R 3.5.3, SPSS Statistics 23.0, and $\mathrm{G}^{\star}$ Power 3.1. Type 1 error was accepted as 0.05

\section{Power Analysis}

In order to calculate the power of the study, the t-test results were used in the multiple regression. Since the independent variables were tested at significance (alpha) levels of both 0.01 and 0.05 , the powers were examined according to both. With an alpha level of 0.05 , a sample size of 70 achieved $82.9 \%$ power to detect an effect size (f2) of 0.1248 using a t-test. With an alpha level of 0.01 , a sample size of 110 achieved $85.9 \%$ power. In the case of a sample size of 170 , the power was over $95 \%$ with both alpha levels (Figure 1).

\section{RESULTS}

The differences in chitotriosidase activity, irisin levels, age, weight, weight-SDS, height-SDS, BMI, BMI-SDS, waist circumference, waist-height ratio, WBC, platelet (Plt), AST, ALT, TC, triglycerides, HDL-C, LDL-C, insulin, HOMA-IR, ISI, and HbAlc between the obese and the control group were statistically significant. The mean value of $\mathrm{ChT}$ in the obese group was $1825.332 \pm 4804.147 \mathrm{nmol} / \mathrm{L} / \mathrm{h}$ and was significantly higher than that in the control group. In contrast, the mean irisin level, $2679.663 \pm 5473.58 \mathrm{pg} / \mathrm{ml}$, was lower than that in the control group (Table 1).

The correlations between irisin and other variables and between $\mathrm{ChT}$ and other variables were investigated for overall observations. Then, all correlation analyses were repeated for the obese group. Overall, ChT and irisin showed a low, negative, and significant correlation. The correlations between ChT and weight, weight-SDS, BMI, BMI-SDS, hemoglobin (Hgb), and hematoctrit (Hct) were low, very positive, and significant. The correlations between irisin and weight-SDS, BMI, BMI-SDS, waist circumference, and waist-height were low, very negative, and significant. In the obese group, $\mathrm{ChT}$ and irisin showed a low, negative, and significant correlation as well. The correlations of ChT with Hgb and Hct were low, positive, and significant. Irisin showed no significant correlations in the obese group (Table 2).

The cutoff point of the continuous variable selected in the model for ChT was 601, with 31.9\% sensitivity, 90.6\% specificity, and an area under the curve of 0.596 . The cutoff point for irisin was 901.4 with $83.5 \%$ sensitivity, $42.4 \%$ specificity, and an area under the curve of 0.617 . In both models, the predictions seemed to overlap. Both cutoff points were between the $60 \%$ and $80 \%$ quantiles. For this reason, we also considered those cutoff points in the quantile regressions to ensure accuracy of the optimal threshold values (Figure 2).

Multiple regression assumptions were also examined. Normal distribution of the residuals (errors), homoscedasticity, multicollinearity, and independence of residuals were examined. However, assumptions were not provided. In particular, there were too many outliers that could not be excluded from the study. We tried some basic transformation of variables, but this did not help in providing assumptions.

The OLS model for irisin as a dependent variable explained approximately $18.25 \%$ of the changes in irisin. The model was significant at a $5 \%$ significance level. BMI-SDS and urea had a statistically significant effect on irisin. In the QR model for ChT as a dependent variable, age had a statistically significant effect on ChT at each of the quantiles. Interestingly, BMI-SDS and glucose were statistically significant at the 80th percentile, where the cutoff point 
Sakarya Med J 2021;11(3):523-532

DURANKUŞ et al., Chitotriosidase Activity and Irisin Level in Obese Children

\begin{tabular}{|c|c|c|c|c|c|}
\hline & Group & Control (n=83) & Obese $(n=91)$ & Test -statistics & $\mathrm{p}$ \\
\hline Chitotriosidase (nmol/L/h) & $-\mathrm{x} \pm \mathrm{s}$ & $438.892 \pm 151.31$ & $1825.332 \pm 4804.147$ & $3123.00 \mathrm{~b}$ & 0.028 \\
\hline $\operatorname{Irisin}(\mathrm{pg} / \mathrm{ml})$ & $-\mathrm{x} \pm \mathrm{s}$ & $2679.663 \pm 5473.58$ & $702.136 \pm 399.83$ & $2963.500 \mathrm{~b}$ & 0.007 \\
\hline Age(years) & $-\mathrm{x} \pm \mathrm{s}$ & $13.106 \pm 2.405$ & $12.332 \pm 2.406$ & $2.130 \mathrm{a}$ & 0.035 \\
\hline \multirow[t]{2}{*}{ Gender } & Female & $44(51.8)$ & $44(48.4)$ & $0.205 c$ & 0.651 \\
\hline & Male & $41(48.2)$ & $47(51.6)$ & & \\
\hline Weight (kg) & $\mathrm{x} \pm \mathrm{s}$ & $46.082 \pm 12.229$ & $66.703 \pm 18.933$ & $1333.00 \mathrm{~b}$ & $<.001$ \\
\hline Weight-SDS (SD) & $-\mathrm{x} \pm \mathrm{s}$ & $-.422 \pm .911$ & $2.157 \pm .966$ & $-18.183 a$ & $<.001$ \\
\hline \multirow[t]{2}{*}{ Weight Percentile (\%) } & Min. & 0.29 & 35.90 & & \\
\hline & Max. & 98.30 & 99.90 & & \\
\hline Height $(\mathrm{cm})$ & $-\mathrm{x} \pm \mathrm{s}$ & $155.410 \pm 14.168$ & $155.510 \pm 13.010$ & $-0.046 a$ & .964 \\
\hline Height -SDS (SD) & $\mathrm{x} \pm \mathrm{s}$ & $-.014 \pm 1.012$ & $.708 \pm 1.153$ & $-4.410 \mathrm{a}$ & $<.001$ \\
\hline \multirow[t]{2}{*}{ Height Per.(\%) } & Min. & 1.30 & 1.30 & & \\
\hline & Max. & 99.10 & 99.10 & & \\
\hline $\operatorname{BMI}(\mathrm{kg} / \mathrm{m} 2)$ & $\mathrm{x} \pm \mathrm{s}$ & $18.771 \pm 2.798$ & $27.074 \pm 4.142$ & $-15.471 \mathrm{a}$ & $<.001$ \\
\hline BMI-SDS & $-\mathrm{x} \pm \mathrm{s}$ & $-.498 \pm 1.028$ & $2.032 \pm .668$ & $-19.485 \mathrm{a}$ & $<.001$ \\
\hline \multirow[t]{2}{*}{ BMI Percentile (\%) } & Min. & 0.10 & 51.90 & & \\
\hline & Max. & 92.10 & 99.90 & & \\
\hline Waist around $(\mathrm{cm})$ & $\mathrm{x} \pm \mathrm{s}$ & $67.959 \pm 7.461$ & $87.956 \pm 13.173$ & $-12.275 \mathrm{a}$ & $<.001$ \\
\hline Waist/Heightn $(\mathrm{cm} / \mathrm{kg})$ & $x \pm s$ & $.438 \pm .041$ & $.565 \pm .065$ & $424.00 \mathrm{~b}$ & $<.001$ \\
\hline WBC (103/uL) & $-\mathrm{x} \pm \mathrm{s}$ & $7217.760 \pm 1733.176$ & $7991.320 \pm 2215.720$ & $3072.00 \mathrm{~b}$ & .019 \\
\hline Hemoglobin (g/dL) & $\mathrm{x} \pm \mathrm{s}$ & $13.031 \pm 1.1855$ & $13.107 \pm .971$ & $3690.50 \mathrm{~b}$ & .600 \\
\hline Hematoctrit (\%) & $\mathrm{x} \pm \mathrm{s}$ & $37.972 \pm 2.929$ & $38.604 \pm 2.752$ & $-1.477 \mathrm{a}$ & .141 \\
\hline Platelet (103/uL) & $\mathrm{x} \pm \mathrm{s}$ & & & $3160.50 \mathrm{~b}$ & .036 \\
\hline Glucose (mg/dL) & $\mathrm{x} \pm \mathrm{s}$ & $90.130 \pm 6.871$ & $91.240 \pm 13.485$ & $3776.50 \mathrm{~b}$ & .787 \\
\hline $\operatorname{AST}(\mathrm{U} / \mathrm{L})$ & $x \pm s$ & $23.916 \pm 10.1078$ & $25.586 \pm 9.272$ & $3111.50 \mathrm{~b}$ & .025 \\
\hline $\operatorname{ALT}(\mathrm{U} / \mathrm{L})$ & $\mathrm{x} \pm \mathrm{s}$ & $15.710 \pm 10.792$ & $22.04 \pm 13.296$ & $2329.00 \mathrm{~b}$ & $<.001$ \\
\hline Urea (mg/dL) & $-\mathrm{x} \pm \mathrm{s}$ & $23.053 \pm 6.423$ & $23.132 \pm 5.841$ & $3769.00 \mathrm{~b}$ & .770 \\
\hline Creatine $(\mathrm{mg} / \mathrm{dL})$ & $\mathrm{x} \pm \mathrm{s}$ & $.539 \pm .127$ & $.508 \pm .116$ & $3239.00 \mathrm{~b}$ & .063 \\
\hline Total Cholesterol (mg/dL) & $\mathrm{x} \pm \mathrm{s}$ & $155.560 \pm 28.971$ & $167.650 \pm 34.814$ & $3096.50 \mathrm{~b}$ & .022 \\
\hline High density lipoprotein (mg/dL) & $\mathrm{x} \pm \mathrm{s}$ & $53.580 \pm 11.364$ & $49.758 \pm 10.214$ & $2.349 \mathrm{a}$ & .020 \\
\hline Triglyceride (mg/dL) & $\mathrm{x} \pm \mathrm{s}$ & $78.865 \pm 32.619$ & $109.571 \pm 52.305$ & $2400.50 \mathrm{~b}$ & $<.001$ \\
\hline Low density lipoprotein (mg/dL) & $\mathrm{x} \pm \mathrm{s}$ & $86.204 \pm 24.732$ & $95.852 \pm 30.898$ & $3162.50 \mathrm{~b}$ & .037 \\
\hline Insulin $(\mathrm{mU} / \mathrm{L})$ & $-\mathrm{x} \pm \mathrm{s}$ & $8.982 \pm 4.277$ & $14.565 \pm 9.862$ & $2258.50 \mathrm{~b}$ & $<.001$ \\
\hline HOMA-IR & $\mathrm{x} \pm \mathrm{s}$ & $2.026 \pm 1.026$ & $3.305 \pm 2.309$ & $2323.50 \mathrm{~b}$ & $<.001$ \\
\hline ISI & $-\mathrm{x} \pm \mathrm{s}$ & $12.726 \pm 6.782$ & $8.503 \pm 4.756$ & $2238.50 \mathrm{~b}$ & $<.001$ \\
\hline HbA1c (\%) & $x \pm s$ & $5.300 \pm .181$ & $5.403 \pm .260$ & $2780.50 \mathrm{~b}$ & .001 \\
\hline TSH (mIU/L) & $\mathrm{x} \pm \mathrm{s}$ & $3.2484 \pm 4.535$ & $3.352 \pm 1.729$ & $3170.50 \mathrm{~b}$ & .039 \\
\hline FT4 & $\mathrm{x} \pm \mathrm{s}$ & $.8186 \pm .1126$ & $.808 \pm .109$ & $0.612 \mathrm{a}$ & .633 \\
\hline
\end{tabular}


Sakarya Med J 2021;11(3):523-532

DURANKUŞ et al., Chitotriosidase Activity and Irisin Level in Obese Children

\begin{tabular}{|c|c|c|c|c|c|c|c|c|}
\hline \multirow[t]{2}{*}{ Spearman's $\rho$} & \multicolumn{4}{|c|}{ Overall $(n=176)$} & \multicolumn{4}{|c|}{ Obese $(n=91)$} \\
\hline & (a) & $\mathrm{p}$ & (b) & $\mathrm{p}$ & (a) & $\mathrm{p}$ & (b) & $\mathrm{p}$ \\
\hline Chitotriosidase (nmol/L/h) (a) & 1.000 & - & $-.188^{\star}$ & .0 .03 & 1.000 & - & $.211^{*}$ & .0 .009 \\
\hline $\operatorname{Irisin}(\mathrm{pg} / \mathrm{ml})(\mathbf{b})$ & $-.188^{\star}$ &. .0 .03 & 1.000 & - & $.211^{\star}$ & .0 .009 & 1.000 & - \\
\hline Age(years) & .097 & .201 & .039 & .604 & .143 & .175 & .062 & .559 \\
\hline Weight (kg) & $.157^{\star}$ & .038 & -.099 & .193 & .052 & .623 & .139 & .188 \\
\hline Weight -SDS(SD) & $.155^{\star}$ & .040 & $-.172^{\star}$ & .023 & -.031 & .771 & .055 & .606 \\
\hline Height (cm) & .064 & .400 & .052 & .495 & .091 & .394 & .080 & .453 \\
\hline Height -SDS (SD) & -.025 & .746 & -.064 & .401 & -.121 & .254 & -.117 & .270 \\
\hline BMI (kg/m2) & $.181^{*}$ & .016 & $-.164^{*}$ & .030 & .015 & .886 & .175 & .098 \\
\hline BMI-SDS & $.169^{*}$ & .025 & $-.190^{*}$ & .011 & -.019 & .857 & .102 & .334 \\
\hline Waist around $(\mathrm{cm})$ & .146 & .053 & $-.149^{*}$ & .049 & -.025 & .811 & .094 & .377 \\
\hline Waist/Heightn $(\mathrm{cm} / \mathrm{kg})$ & .117 & .121 & $-.179^{*}$ & .018 & -.043 & .685 & .033 & .757 \\
\hline WBC (103/uL) & -.078 & .303 & .000 & 1.000 & -.075 & .479 & -.061 & .563 \\
\hline Hemoglobin (g/dL) & $.176^{*}$ & .019 & -.019 & .800 & $.285^{\star *}$ & .006 & .116 & .274 \\
\hline Hematoctrit (\%) & $.159^{*}$ & .035 & -.040 & .602 & $.220^{*}$ & .036 & .018 & .867 \\
\hline Platelet $(103 / \mathrm{uL})$ & -.010 & .896 & .013 & .868 & -.068 & .525 & .056 & .596 \\
\hline Glucose (mg/dL) & -.056 & .459 & -.014 & .857 & -.154 & .145 & -.029 & .784 \\
\hline $\operatorname{AST}(\mathrm{U} / \mathrm{L})$ & .015 & .841 & -.091 & .229 & .107 & .313 & -.073 & .494 \\
\hline $\operatorname{ALT}(\mathbf{U} / \mathrm{L})$ & -.001 & .995 & -.116 & .126 & -.001 & .993 & -.049 & .643 \\
\hline Urea (mg/dL) & -.079 & .295 & .106 & .162 & .022 & .835 & -.064 & .547 \\
\hline Creatine (mg/dL) & -.005 & .950 & -.065 & .391 & .019 & .862 & -.133 & .208 \\
\hline Total Cholesterol (mg/dL) & .033 & .664 & -.048 & .524 & .067 & .527 & -.063 & .552 \\
\hline High density lipoprotein (mg/dL) & .041 & .585 & .043 & .571 & .070 & .509 & .028 & .791 \\
\hline Triglyceride (mg/dL) & -.005 & .946 & -.096 & .205 & -.126 & .232 & -.026 & .805 \\
\hline Low density lipoprotein (mg/dL) & .020 & .797 & -.070 & .354 & .104 & .326 & -.080 & .452 \\
\hline Insulin (mU/L) & .036 & .635 & -.121 & .110 & -.178 & .091 & -.013 & .899 \\
\hline HOMA-IR & .023 & .760 & -.113 & .136 & -.205 & .052 & -.005 & .962 \\
\hline ISI & -.072 & .342 & .132 & .081 & .118 & .264 & .036 & .734 \\
\hline HbAlc (\%) & .009 & .907 & -.072 & .342 & -.096 & .365 & -.082 & .438 \\
\hline TSH (mIU/L) & -.026 & .732 & -.028 & .716 & -.048 & .650 & -.102 & .334 \\
\hline FT4 & -.027 & .721 & .000 & .998 & -.070 & .509 & -.038 & .722 \\
\hline
\end{tabular}


Sakarya Med J 2021;11(3):523-532

DURANKUŞ et al., Chitotriosidase Activity and Irisin Level in Obese Children

\begin{tabular}{|c|c|c|c|c|c|c|c|c|c|c|c|}
\hline & \multirow[t]{2}{*}{ Variables } & \multirow[t]{2}{*}{ OLS } & \multicolumn{9}{|c|}{ Quantile Regression (QR) } \\
\hline & & & $\% 10$ & $\% 20$ & $\% 30$ & $\% 40$ & $\% 50$ & $\% 60$ & $\% 70$ & $\% 80$ & $\% 90$ \\
\hline \multirow{3}{*}{ (a) } & Age & $247.18^{\star *}$ & $13.16^{*}$ & $15.16^{*}$ & $19.40^{*}$ & $22.35^{*}$ & $26.48^{*}$ & 23.19 & 19.99 & 15.92 & $59.41^{*}$ \\
\hline & BMI-SDS & $596.58^{\star *}$ & 14.12 & 16.16 & 12.82 & 19.84 & 23.68 & $37.07^{*}$ & $33.17^{*}$ & $55.10^{* *}$ & $89.37^{\star *}$ \\
\hline & Glucose(mg/dL) & $-27.10^{*}$ & 0.98 & 1.05 & 1.07 & 1.02 & 1.03 & 2.02 & 3.12 & $4.62^{*}$ & 0.30 \\
\hline \multirow{2}{*}{ (b) } & BMI-SDS & $-521.04^{\star *}$ & -42.35 & -22.12 & -15.00 & -12.47 & -42.71 & $-99.09^{*}$ & $-97.91^{\star}$ & $-157.29^{* *}$ & $-370.73^{*}$ \\
\hline & Urea (mg/dL) & $87.89^{* *}$ & $15.70^{\star *}$ & $18.47^{* *}$ & $22.88^{\star *}$ & $25.17^{\star *}$ & $30.80^{* *}$ & $40.54^{* *}$ & $46.61^{\star *}$ & $60.04^{* *}$ & $104.94^{* *}$ \\
\hline
\end{tabular}

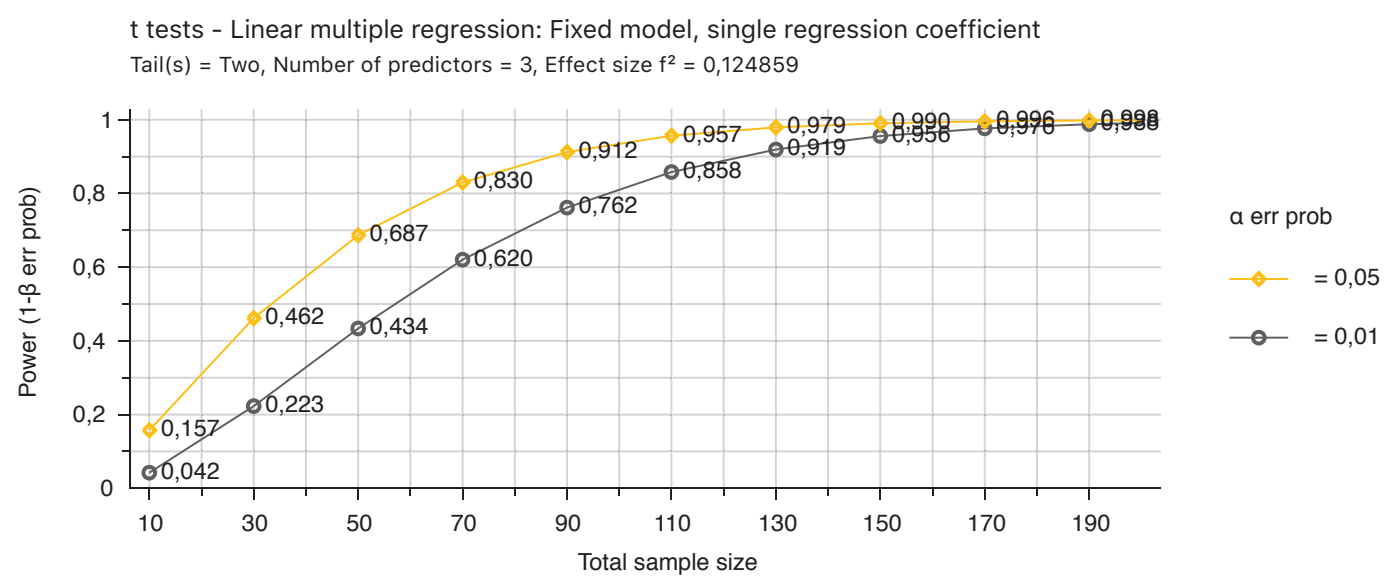

Figure 1. Results of Power Analysis according to 0.01 and 0.05 Alpha Error Probabilities

The ROC curve of Chitotriosidase with optimal threshold values.

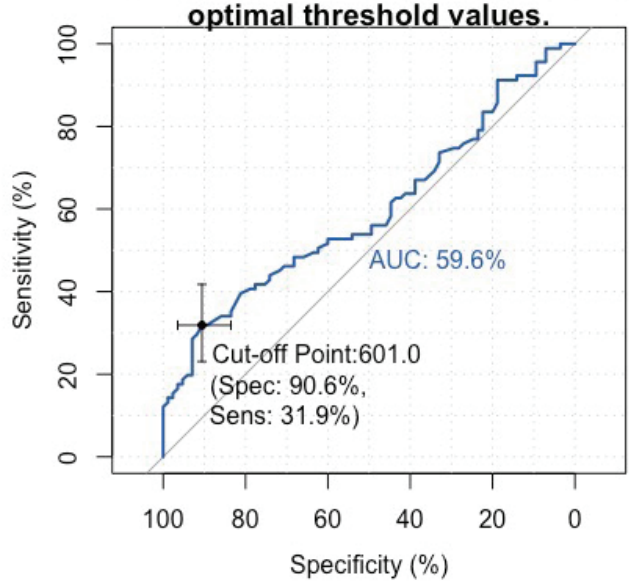

The ROC curve of Irisin with

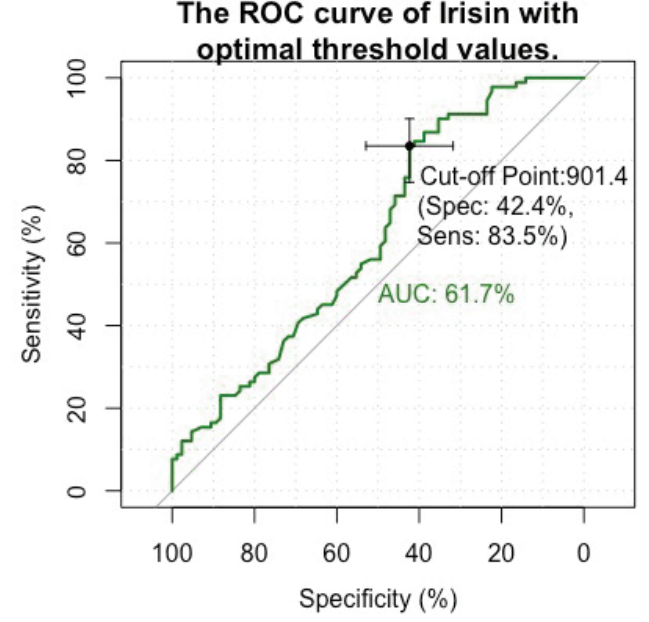

Figure 2. The ROC curve analysis of Chitotriosidase and Irisin according to Groups 
was found. In the QR model for irisin as a dependent variable, urea had a statistically significant effect at each of the quantiles. As in the other QR model, BMI-SDS was statistically significant at the 60th percentile, where the cutoff point was found. Based on the results of both QR models, we concluded that these cutoff points were accurate (Table 3).

The red solid lines in Figures $3(\mathrm{a}-\mathrm{c})$ and $4(\mathrm{a}-\mathrm{b})$ show the coefficients of the OLS model. The red dashed lines show the $95 \%$ confidence intervals. The black fixed-point lines show the values of the coefficients of the QR model at different quantiles. The gray ranges around them show the $95 \%$ confidence intervals. The red solid lines show that the coefficients of the independent variables were affected by the outliers. The black lines show opposite results compared to the red lines, yielding more robust results.

\section{DISCUSSION}

In this study, we found significantly higher values of serum ChT activity and significantly lower levels of serum irisin in children with obesity than in healthy controls. We also found that serum ChT activity and irisin levels correlated with each other and other several metabolic parameters. Furthermore, we succeeded in predicting cutoff values for both serum ChT activity and irisin levels in children with obesity.

Human ChT activity is a well-established tool for monitoring the effects of treatment for GD. It was first regarded as a significant diagnostic tool for monitoring the efficacy of treatments for Gaucher's disease (GD) and glucocerebrosidase deficiency. However, accumulating data suggest that ChT activity is also significantly associated with atherosclerosis neurodegenerative disorders, and non-alcoholic steatohepatitis. Relatively recent research has shown that serum ChT activity predicts endothelial dysfunction in uncomplicated, newly diagnosed type 2 diabetes mellitus (DM) patients. ${ }^{16-18}$ However, only one study has investigated serum ChT activity in children with obesity. ${ }^{21}$ Sev- eral studies have reported that ChT activity is associated with intracellular lipid accumulation in GD. ${ }^{22-24}$ Beside the role of ChT activity in GD, it has been shown that the macrophages within atherosclerotic vascular plaques produce high amounts of ChT, which means that serum ChT activity might correlate with the amount of lipid-loaded macrophages in atherosclerotic plaques. ${ }^{25}$ Regarding this shared mechanism, it seems reasonable to investigate serum ChT activity in children with obesity. Kundak et al., authors of the only study on serum ChT activity in children with obesity, reported that it was significantly higher in children with obesity than in lean children. However, as they found no significant correlations between serum ChT activity and high-sensitivity CRP (hsCRP), HOMA-IR, and BMI-SDS, they concluded that it may not be a useful tool for monitoring systemic low-grade inflammation and insulin resistance in obese subjects and called for further confirmation studies. ${ }^{21}$ Our results confirm Kundak et al.s findings in terms of the significantly higher values of serum ChT activity in children with obesity than in normal-weight children. Additionally, we demonstrated a significant association between serum ChT activity and BMISDS in quantile regression and multiple linear regression analyses and determined a significant cutoff value for ChT activity.

Myokines are produced with exercise in both rodents and humans. They have been shown to be associated with browning in adipose tissue and to increase energy values in mice without interpreting movement and food intake. Thus, this mechanism has been found to reduce obesity and improve glucose homeostasis. Like ChT activity, irisin has been associated with inflammation in obese individuals. ${ }^{19}$ Regarding irisin, several studies have investigated the association between circulating irisin, adiposity, and obesity in humans. However, their results can be considered inconsistent, as they have variably reported a positive correlation of serum irisin levels with BMI and adiposity, a negative correlation between circulating irisin levels and BMI, and no significant correlation. ${ }^{26,27}$ It is well estab- 
lished that there is a significant imbalance in cytokine secretion in obesity, which is a predictor of developing insulin resistance and type 2 diabetes mellitus. ${ }^{28}$ Irisin has been suggested to have a role in inflammation, although this has not been well established. Irisin treatment has been reported to suppress the expression of pro-inflammatory cytokines, nuclear factor-kappa B (NF- $\kappa$ B), TNF- $\alpha$, and IL-6 in a concentration-dependent manner. ${ }^{29}$ Recently, Shim et al. found that irisin levels were low in overweight/children with obesity with metabolic syndrome. They determined a possible cutoff value to distinguish between children with metabolic syndrome and overweight/children with obesity with $75 \%$ sensitivity and $94 \%$ specificity, concluding that irisin is a candidate as a biomarker of metabolic syndrome in prepubertal children. ${ }^{30}$ In line with Shim et al., we found that serum irisin levels were significantly lower in children with obesity than in healthy controls. We also determined a cutoff point of 901.4 for irisin, with $83.5 \%$ sensitivity, $42.4 \%$ specificity, and an area under the curve of 0.617 . Quantile regression and multiple linear regression analyses revealed that BMI-SDS was significantly associated with serum irisin levels.

This is the first study to investigate the roles of serum ChT activity and irisin in children with obesity simultaneously. We found a significant correlation between serum ChT activity and irisin levels in obesity. Regarding the inflammatory role of serum activity in several diseases, we can argue that our results confirm the inflammatory role of irisin in childhood obesity.

The main limitation of this study is that we could not investigate several inflammatory markers, such as CRP and interleukins, which would have strengthened our results in terms of illuminating the inflammatory roles of serum ChT activity and irisin levels. However, we believe that this limitation would be the object of further studies. Another limitation is that we could not measure other circulating myokines or adipokines like previous stuides that may be simultaneously secreted from muscle and adipose tissue.

\section{CONCLUSION}

In conclusion, this study is the first to show decreased serum both serum ChT activity and irisin level and ChT's association with irisin levels in children with obesity. We argue that $\mathrm{ChT}$ and irisin should be explored as potential biomarkers of metabolic syndrome in children with obesity. However, further studies are needed to confirm our results.

\section{Clinical Significance}

Children who are suspected for developing obesity will be able to determine. Thus, early interventions can be performed after analyzing of serum ChT and irisin will be taken into account in such children. However, there will be further studies to confirm our suggestions.

\section{Acknowledgement}

None.

Ethics

\section{Ethics Committee Approval}

The present study was approved by Medeniyet University Non-Invasive Clinic Research Ethical Committee ( Date: 03 July 2019; Approval Number: 2019/303).

\section{Informed Consent}

Informed consent was obtained from the parents of all children before their participation.

\section{Disclosure}

No conflict of interest to disclose and industry relationship.

\section{Authors' Contribution}

FD, Data Collection or Processing: OS,EŞ,RD,YA Analysis or Interpretation: NP, Literature Search: FD,RD,EŞ,ESS

\section{Writing}

FD 
Sakarya Med J 2021;11(3):523-532

DURANKUŞ et al., Chitotriosidase Activity and Irisin Level in Obese Children

\section{References}

1. Kawasaki M, Arata N, Miyazaki C, et al. Obesity and abnormal glucose tolerance in offspring of diabetic mothers: A systematic review and meta-analysis. PLoS One 2018 12;13(1):e0190676. doi:10.1371/journal.pone.0190676

2. Kumar S, Kelly AS. Review of Childhood Obesity: From Epidemiology, Etiology, and Comorbidities to Clinical Assessment and Treatment. Mayo Clin Proc Published online 2017. doi:10.1016/j.mayocp.2016.09.017

3. Oken E, Levitan EB, Gillman MW. Maternal smoking during pregnancy and child overweight: Systematic review and meta-analysis. Int J Obes 2008;32(2):201-10. doi:10.1038/ sj.ijo.0803760

4. Umer A, Kelley GA, Cottrell LE, Giacobbi P, Innes KE, Lilly CL. Childhood obesity and adult cardiovascular disease risk factors: A systematic review with meta-analysis. BMC Public Health 2017; 17(1):683. doi:10.1186/s12889-017-4691-z

5. Alejandro DF, Pablo CL, Pilar HJ, Daniela AS. The obese child in the Intensive Care Unit. Update. Arch Argent Pediatr. 2016;114(3):258-166. doi:10.5546/aap.2016.eng.258

6. Rajjo T, Mohammed K, Alsawas $M$, et al. Treatment of pediatric obesity: An umbrella systematic review. J Clin Endocrinol Metab 2017;102(3):763-775. doi:10.1210/jc.2016-2574

7. Trandafir LM, Temneanu OR. Pre and post-natal risk and determination of factors for child obesity. J Med Life 2016;9(4):386-391.

8. Winck AD, Heinzmann-Filho JP, Soares RB, Silva JS da, Woszezenki CT, Zanatta LB. Effects of obesity on lung volume and capacity in children and adolescents: a systematic review. Rev Paul Pediatr 2016;34(4):510-517. doi:10.1016/j.rppede.2016.03.013

9. De Vries MA, Klop B, Janssen HW, Njo TL, Westerman EM, Cabezas MC. Postprandial infl ammation: Targeting glucose and lipids. In: Advances in Experimental Medicine and Biology. ; 2014 doi:10.1007/978-3-319-07320-0_12

10. Yudkin JS. Adipose tissue, insulin action and vascular disease: Inflammatory signals. In: International Journal of Obesity 2003;27 Suppl 3:S25-8.doi:10.1038/sj.ijo.0802346

11. Arslan N, Erdur B, Aydin A. Hormones and cytokines in childhood obesity. Indian Pediatr 2010;47(10):829-39. doi:10.1007/s13312-010-0142-y

12. Calle EE, Kaaks R. Overweight, obesity and cancer: Epidemiological evidence and proposed mechanisms. Nat Rev Cancer 2004;4(8):579-91. doi:10.1038/nrc1408

13. Ridker PM. High-sensitivity C-reactive protein: Potential adjunct for global risk assessment in the primary prevention of cardiovascular disease. Circulation 2001;104(22):E127. doi:10.1161/01.CIR.103.13.1813

14. Fogarty AW, Glancy C, Jones S, Lewis SA, McKeever TM, Britton JR. A prospective study of weight change and systemic inflammation over 9 y. Am J Clin Nutr 2008 ;87(1):30-5.. doi:10.1093/ajcn/87.1.30

15. Saltevo J, Vanhala M, Kautiainen H, Laakso M. Levels of adiponectin, C-reactive protein and interleukin-1 receptor antagonist are associated with the relative change in body mass index between childhood and adulthood. Diabetes Vasc Dis Res 2007;4(4):328-31. doi:10.3132/dvdr.2007.060
16. Artieda $M$, Cenarro A, Gañán A, et al. Serum chitotriosidase activity is increased in subjects with atherosclerosis disease. Arterioscler Thromb Vasc Biol 2003 ;23(9):1645-52. doi:10.1161/01.ATV.0000089329.09061.07

17. Canudas J, Cenarro A, Civeira F, et al. Chitotriosidase genotype and serum activity in subjects with combined hyperlipidemia: Effect of the lipid-lowering agents, atorvastatin and bezafibrate. Metabolism 2001;50(4):447-50. doi:10.1053/meta.2001.21696

18. Sonmez A, Haymana C, Tapan S, et al. Chitotriosidase activity predicts endothelial dysfunction in type-2 diabetes mellitus. Endocrine 2010;37(3):455-9. doi:10.1007/s12020-0109334-4

19. Kundak AA, Tascilar ME, Abaci A, et al. Serum chitotriosidase activity: Is it a new infl ammatory marker in obese children? J Pediatr Endocrinol Metab 2012;25(1-2):63-7. doi:10.1515/JPEM.2011.329

20. De Onis M. 4.1 The WHO child growth standards. World Rev Nutr Diet. Published online 2015. doi:10.1159/000360352

21. Giraldo P, Cenarro A, Alfonso P, et al. Chitotriosidase genotype and plasma activity in patients with type 1 gaucher's disease and their relatives (carriers and non-carriers). Haematologica 2001;86(9):977-84.

22. Hollak CEM, Van Weely S, Van Oers MHJ, Aerts JMFG. Marked elevation of plasma chitotriosidase activity. A novel hallmark of Gaucher disease. J Clin Invest 1994;93(3):1288-92. doi:10.1172/JCI117084

23. Pastores GM, Berglund L, Desnick RJ. Lipoprotein metabolism in type l gaucher disease patients on enzyme therapy. J Investig Med Published online 1996.

24. Eckardt K, Taube A, Eckel J. Obesity-associated insulin resistance in skeletal muscle: Role of lipid accumulation and physical inactivity. Rev Endocr Metab Disord 2011;12(3):163-72. doi:10.1007/s11154-011-9168-2

25. Crujeiras AB, Zulet MA, Lopez-Legarrea P, et al. Association between circulating irisin levels and the promotion of insulin resistance during the weight maintenance period after a dietary weight-lowering program in obese patients. Metabolism 2014;63(4):520-31. doi:10.1016/j.metabol.2013.12.007

26. Stengel A, Hofmann T, Goebel-Stengel M, Elbelt U, Kobelt P, Klapp BF. Circulating levels of irisin in patients with anorexia nervosa and different stages of obesity-Correlation with body mass index. Peptides 2013;39:125-30. doi:10.1016/j.peptides.2012.11.014

27. Fantuzzi G. Adipose tissue, adipokines, and inflammation. J Allergy Clin Immunol. 2005;115(5):911-9. doi:10.1016/j.jaci.2005.02.023

28. Dong J, Dong Y, Dong Y, Chen F, Mitch WE, Zhang L. Inhibition of myostatin in mice im proves insulin sensitivity via irisin-mediated cross talk between muscle and adipose tissues. Int J Obes 2016;40(3):434-442. doi:10.1038/ijo.2015.200

29. Shim YS, Kang MJ, Yang S, Hwang IT. Irisin is a biomarker for metabolic syndrome in prepubertal children. Endocr J 2018;65(1):23-31. doi:10.1507/endocrj.EJ17-0260 